\title{
Social Support and Self- Care Behaviour among Heart Failure Patients
}

\author{
Husna Ahmad Ainuddin', Siti Salwa Talib', Mohd Zhafran Zainal Abidin², Diana Katiman² \\ ${ }^{1}$ Department of Occupational Therapy, Faculty of Health Sciences, \\ 2Department of Medicine, Faculty of Medicine, \\ Universiti Teknologi MARA, Malaysia
}

husnaa9866@uitm.edu.my, salwa046@uitm.edu.my, zhafran@salam.uitm.edu.my, diana@uitm.edu.my Tel. +60332584543

\begin{abstract}
Heart failure is a disease that could cause a significant medical burden. This study aims to determine the relationship between social support and selfcare behaviour among heart failure patients. Thirty patients from a Clinical Training Centre participated in this cross-sectional study. Instruments used in the study were the Multidimensional Scale of Perceived Social Support (MSPSS) and The European Heart Failure Self-care Behaviour Scale-9 item (EHFSCBC). The results showed that there was a relationship between social support and self-care behaviour $(r=0.40, p<0.05)$. Awareness of the impact of social support on self-care behaviour is vital for heart failure patients and their families.
\end{abstract}

Keywords: Heart failure, social support, self-care behaviour

eISSN: 2398-4287 @ 2019. The Authors. Published for AMER ABRA cE-Bs by e-International Publishing House, Ltd., UK. This is an open access article under the CC BYNC-ND license (http://creativecommons.org/licenses/by-nc-nd/4.0). Peer-review under responsibility of AMER (Association of Malaysian Environment-Behaviour Researchers), ABRA (Association of Behavioural Researchers on Asians) and cE-Bs (Centre for Environment-Behaviour Studies), Faculty of Architecture, Planning \& Surveying, Universiti Teknologi MARA, Malaysia.

DOI: https://doi.org/10.21834/e-bpj.v4i12.1906

\subsection{Introduction}

At present, approximately 26 million people worldwide are living with heart failure (Ponikowski et al., 2014). Limited single-centre data in Malaysia and Singapore suggest that the prevalence of heart failure in Southeast Asian countries is higher compared with countries globally (4.5-6.7\% vs $0.5-2 \%$, respectively) (Lam, 2015; Ponikowski et al., 2014). Symptom management was identified as a top priority for end of life patients with a chronic illness, including those with heart failure (Singer, Martin \& Kelner, 1999; Stanek et al., 2000). Nonpharmacological interventions of symptoms of chronic heart failure include self-care reinforcement on maintaining health in daily activities (National Heart Foundation Information, 2012). Self-care for heart failure patients is generally defined as a health monitoring and disease management practice in which outcomes and behaviours result in maintained stability, identification of changes in condition, and detailed responses (Riegel \& Dickson, 2008; Riegel, Jaarsma \& Stromberg, 2012).

Evidence showed that there are positive relationships between perceived social support and hospital readmissions, following treatment plans, and better self-care (Chan et al., 2019; Sayer et al. 2008). Furthermore, Gallagher, Luttik, and Jaarsma (2011) explained partners who provide a high level of support might actively promote heart failure patients' self-care. A few studies also found that a supportive environment was crucial to create positive emotions and to improve self-care management in patients with chronic heart failure (Ming et al., 2011; Sebern \& Riegel, 2009). Thus, it is crucial to understand the relationship between social support and heart failure patients' self-care and whether these patients are receiving adequate social support from family members, friends, and others. However, in Malaysia, the influences between social support towards self-care behaviour are not yet determined. The specific objectives of this study were as follows: (i) to determine the differences between demographic variables with social support and self-care behaviour and (ii) to establish the relationship between social support and self-care behaviour among heart failure patients.

eISSN: 2398-4287 @ 2019. The Authors. Published for AMER ABRA cE-Bs by e-International Publishing House, Ltd., UK. This is an open access article under the CC BYNC-ND license (http://creativecommons.org/licenses/by-nc-nd/4.0). Peer-review under responsibility of AMER (Association of Malaysian Environment-Behaviour Researchers), ABRA (Association of Behavioural Researchers on Asians) and cE-Bs (Centre for Environment-Behaviour Studies), Faculty of Architecture, Planning \& Surveying, Universiti Teknologi MARA, Malaysia. DOI: https://doi.org/10.21834/e-bpj.v4i12.1906 


\subsection{Literature Review}

Heart failure is defined as the abnormal condition in which disturbed cardiac performance is primarily responsible for the inability of the heart to pump blood at a rate appropriate with systemic metabolic requirements (Mason, 1976). Currently, heart failure is one of the primary cardiovascular diseases (Heo et al., 2008) and a leading cause of death and illness in Asia (Sakata \& Shimokawa, 2013). Some of the common risk factors of heart disease include hypertension, diabetes, high cholesterol level, and smoking (Gordon \& Kannel, 1982; Kannel \& McGee, 1979; Gordon et al., 1977). The symptoms of pain, oedema, constipation, nausea, dyspnea, sleep disturbance and psychological distress were also often reported in heart failure patients (Albert et al., 2009; Barnes et al., 2006; Bekelman et al., 2007; Carels et al., 2004). In addition to the distressing physical symptoms of heart failure, its psychosocial effects have been widely reported, especially on well-being (Brännström et al. 2006).

Social support is defined as a process of interacting with others (Gottlieb, 2000), which includes emotional and informational support, physical support, affectionate support, and positive social interaction (Sherbourne \& Stewart, 1991). Without assistance from surroundings, this will create stress and give patients a significant impact on their life. According to Mahrer-Imhof, Hoffman, and Froelicher (2007), patients commonly have a positive relationship with their spouses. This scenario is also similar in a study by Chan et al. (2019) in which they reported that participants had received high social support from a spouse (41.1\%), followed by family (24.8\%) and friends (21.4\%). This element of social support is essential and can bring a positive effect, such as in improving self- care, able to give full commitment towards treatment plans, and to reduce ward admissions (Chan et al., 2019; Sayer et al. 2008).

Self-care is 'a range of care activities deliberately engaged throughout life to promote physical, mental, and emotional health, maintain growth, and prevent disease performed by the individual on their behalf, for their families, or communities, and includes care by others' (Godfrey et al., 2011). Self-care behaviours in heart failure include compliance to medication, exercise, and diet plans, leading a healthy lifestyle and preventing obesity, controlling the signs and symptoms of the illness (Riegel et al., 2009). However, self-care is frequently difficult for patients and several studies reported that patients struggle to perform self-care because of depression, comorbid conditions, sleep disturbances, poor health literacy, problems with healthcare systems and impaired cognition (Riegel et al., 2009; Jones et al., 2012)

The American College of Cardiology Foundation and the American Heart Association stated that self-care in heart failure is the key to improve life quality and reduce mortality rates (Yancy et al. 2013). Gallagher, Luttik, and Jaarsma (2011) believe that social support can have an impact on better self-care to heart failure patients. A study reported that improvements in perceived social support enhance self-care behaviours in heart failure patients (Khaledi et al. 2015). A study by Daus et al. (2018) reported that social support significantly moderated the relationship between comorbidities and self-care in which social support accounted for $6 \%$ of the variance in self-care maintenance and $8 \%$ of the variance in self-care monitoring. Additionally, a study by Gallagher, Luttik \& Jaarsma (2011) also reported that high social support is associated with better self-care behaviour in aspects of medication adherence, exercise, weight consultation, and restricting fluids intake.

\subsection{Methodology}

\subsection{Study Design}

A cross-sectional design was selected for this study. The proposed study was conducted at a public university's clinical training centre in Sungai Buloh, Malaysia.

\subsection{Sample Size and Sampling}

Participants selected were patients that were diagnosed with heart failure. Purposive sampling method was chosen for this research with a sample size of 30. Roscoe (1975) stated that for a cross-sectional study, a minimum of 30 participants is required. The inclusion criteria of participants for this study are 1) heart failure patients aged 18 years old and above and are classified as class II, III or IV according to the New York Heart Association (NYHA) functional classification, 2) participants should also be able to understand English as the original language of the instruments are in English, 3) participants must have a Left Ventricular Ejection Fraction (LVEF) rate of below $40 \%$. Heart failure patients who have physical disabilities or have been diagnosed with any mental illnesses are excluded from the study.

\subsection{Instruments}

All authors of the instruments adopted for this study gave their permission for use. Two instruments used for this study are The Multidimensional Scale of Perceived Social Support (MSPSS) and The European Heart Failure Self-care Behaviour Scale (EHFSCBS) -9 item.

The MSPSS is an assessment to assess an individual's perception of the social support that the one receives from family, friends, and significant others. It measured by using the 7 points self- rating Likert scale (ranging from $1=$ Very strongly disagree- $7=V e r y$ strongly agree) and can be completed in 10 minutes or less. The scoring is done by summing the total score. The overall score can be calculated by adding all the 12 items and then dividing by 12. In general, a higher score indicates higher perceived social support(Zimet, Dahlem, Zimet \& Farley, 1988). In addition to this, any mean scale score ranging from 1 to 2.9 could be considered low support; a score of 3 to 5 could be regarded as moderate support; a score from 5.1 to 7 could be viewed as high support. Most investigations have revealed MSPSS to be a three-factor construct that demonstrates good to excellent internal consistency and test-retest reliability (Pedersen, Spinder, Erdman \& Denollet 2009; Zimet, Dahlem, Zimet \& Farley 1988). 
The EHFSCBS-9 item version is an assessment to assess self-care behaviour in heart failure patients and comprised of nine items rated on a 5-point scale between 1 (I completely agree) and 5 (I completely disagree). The total raw scores are then converted to a standardized score from 0 to 100 with a higher score indicating better self-care (Jaarsma, Arestedt, Martensson, Dracup \& Stromberg 2009; Wagenaar et al., 2017). This scale has Cronbach alpha's values ranging from 0.69 to 0.93 , and the total Cronbach alpha of this assessment was 0.80 , with excellent internal consistency (Vellone et al. 2014). The reliability of this assessment showed a good coefficient level in three factors, which are 0.77 for the provider- based adherence, 0.82 for the autonomous- based adherence, and 0.95 for consulting behaviours factors (Vellone et al. 2014).

\subsection{Data Procedure and Collection}

Ethical approval was granted from the Research Ethics Committee, Universiti Teknologi MARA, in Shah Alam, Malaysia. The data was collected by identifying participants that fulfilled the inclusion and exclusion criteria. The participants were then explained about the study in detail and asked whether if they would like to participate. Participants who gave verbal consent and have agreed with the terms of participating in the study were asked to sign a written permission before proceeding to ensure the confidentiality of all the information gathered. The questionnaires were given to the participant to fill up, and a researcher was present to assist the participants if they had any difficulty in understanding and answering the questions. Both the questionnaires used in this study are self-administered. Thirty questionnaires of participants were successfully collected.

\subsection{Data Analysis}

All the statistical analyses in this study were performed using the Statistical Package of Social Science (SPSS) software version 21. The data had been analysed for normality, and the results showed that the data is normally distributed $(p>0.05)$. Thus, parametric analyses, namely T-test, ANOVA, and Pearson, were conducted.

\subsection{Findings}

\subsection{Demographic Data}

The total of the participants of this study was 30 heart failure patients, which is consists of 21 males and nine females. $66.7 \%$ of the participants were Malay. Many of the participants were married $(n=27,90 \%)$ and had a household income of below RM3855 ( $n=23$, $76.7 \%$ ). $93.3 \%$ ( $n=28$ ) of participants had an ejection fraction value of $20-40 \%$. The sociodemographic data of participants are shown in Table 1.

Table 1. Distribution of the demographic characteristic among the participants

\begin{tabular}{lcc}
\hline Characteristic & Frequency $(\mathrm{n}=30)$ & Percentage $\%$ \\
\hline Gender & 21 & 70.0 \\
Male & 9 & 30.0 \\
Female & & \\
Race & 20 & 66.7 \\
$\quad$ Malay & 10 & 33.3 \\
Non-Malay (Chinese and Indian) & & \\
Age & 8 & 26.7 \\
30-49 & 17 & 56.7 \\
$50-69$ & 5 & 16.6 \\
70 and above & & 13.3 \\
Education & 4 & 70.0 \\
No Formal Education & 21 & 16.7 \\
Primary/Secondary & 5 & \\
Tertiary & & 90.0 \\
Marital Status & 27 & 10.0 \\
Married & 3 & \\
Single/Widowed & & 76.7 \\
Household Income & & 23.3 \\
<RM3855 & 23 & 6.7 \\
RM3865-8319 & 7 & 93.3 \\
Ejection Fraction & & \\
<20\% & 2 & 16.7 \\
20-40\% & 28 & 33.3 \\
Health Status & & 23.3 \\
No illness & 5 & 26.7 \\
Diabetes & 10 & \\
Hypertension & 7 & \\
Both & 8 & \\
\hline & &
\end{tabular}




\subsection{Social Support}

Meanwhile, Table 2 shows the mean score of social support. Based on our findings, family support received the highest mean score for social support. Overall, the participants had high social support.

Table 2. Mean score of social support

\begin{tabular}{ll}
\hline Type of Support & Mean (SD) \\
\hline Significant others (spouse, partner) & $5.96(1.41)$ \\
Family & $6.33(0.81)$ \\
Friends & $4.47(1.40)$ \\
Total Score & $5.58(0.86)$ \\
\hline
\end{tabular}

\subsection{Differences between demographic variables with social support and Self Care Behaviour}

All the demographic variables showed no significant differences with social support and self-care behaviour ( $p>0.05)$. Table 3 shows the differences between demographic variables with social support and self-care behaviours.

Table 3 Differences between Demographic Variables with Social Support and Self -Care Behaviour

\begin{tabular}{lll}
\hline & Social Support & Self-Care Behaviour \\
\hline Variable & p-value & p-value \\
Gender & 0.10 & 0.38 \\
Age & 0.10 & 0.37 \\
Race & 0.22 & 0.91 \\
Education Level & 0.78 & 0.80 \\
Household Income & 0.50 & 0.66 \\
Health Status & 0.71 & 0.63 \\
\hline
\end{tabular}

*statistical significance $(p<0.05)$

\subsection{Relationship between Social Support and Self-Care Behaviour}

There was a significant positive relationship between social support and self-care behaviour $(r=0.40, p<0.05)$, which indicates a moderate correlation. Table 4 reports the correlation between social support and self-care behaviour.

Table 4. Relationship between Social Support and Self-Care Behaviour

\begin{tabular}{lc}
\hline Variables & Social Support (r-value) \\
\hline Self-Care Behaviour (r-value) & $0.40^{*}$ \\
\hline \multicolumn{2}{c}{ The statistical coefficient refers to Pearson's correlation coefficient. } \\
*statistical significance $(p<0.05)$
\end{tabular}

\subsection{Discussion}

\subsection{Social Support}

This study reveals that family support has the highest mean score when compared to other sources of support, followed by significant others. As $90 \%$ of the participants are married, this is evident that individuals who stay together with their partner or family received greater support (Sayers et al. 2008). Furthermore, living alone can result in lower levels of social support (Arestedt et al., 2013). Besides family support, a study by Mahrer-Imhof, Hoffman, and Foelicher (2007) also reported that social support from a spouse has a high impact on heart failure patients' self-care and wellbeing. Additionally, a study by Gallagher, Luttik, and Jaarsma (2011) reported that most patients rated their partners' support at a high level for practical support (82\%), emotional support (87\%), and attention to symptoms (95\%). The types of social support that are given to heart failure patients include emotional or informational support, tangible support, affectionate support, and positive social interaction (Yunus and Sharoni, 2016).

\subsection{Differences in demographic data on Social Support and Self Care Behaviour}

Based on this study's findings, demographic variables with social support showed no significant differences. This result is in line with previous studies by Yunus and Sharoni (2016), who also reported that in their study, age, gender, race, education level, and disease duration did not influence and give any impact to social support.

This study also found out that there were no significant differences between self-care behaviour with gender, age, race, income, educational level, and health status. This is because there was a small number of participants in the study. Thus, most of the groups within variables had to be recategorised (e.g., for race, instead of Malay $(n=20)$ Chinese $(n=6)$ and Indian $(n=4)$ respectively, the 
researcher reclassified to Malay and Non-Malay for analysis). This result is similar to a study by Gallagher, Luttik, and Jaarsma (2011) that reported that no demographic or clinical characteristic was associated with self-care behaviour.

\subsection{Relationship between Social Support and Self-Care Behaviours}

Social support and self-care behaviour were found to have a moderate correlate in this study $(r=0.40, p<0.05)$. A study by Khaledi et al. (2015) and Gallagher, Luttik and Jaarsma (2011) also reported similar findings that showed a positive relationship between perceived social support with self-care behaviour, the higher the perceived social support, the better the self-care behaviour among heart failure patients. The individual who received tremendous social support was able to accomplish healthy self-care behaviours.

\subsection{Limitation and Recommendations of the study}

There are a few limitations to the study. The sample size of the study is relatively small; hence, most of the groups within the variables had to be recategorised for analysis. Although it was normally distributed, a small size can limit the generalization of the population. It is recommended to conduct similar research on a larger scale and investigate the prevalence of heart failure patients in Malaysia.

Another limitation was that the research instruments were not available in the Malay language. This made it difficult to recruit participants as many of the heart failure patients were unable to understand English and must be excluded from this study.

Future recommendations for this study are to include measures of functional status, psychological well-being, and quality of life of heart failure patients as self-care behaviour is depended on several factors. Investigation of the types of social support given to the patients, such as financial support, is also warranted as it could also influence self-care behaviours. Self-efficacy of patients should also be investigated as it is an essential factor for an older adult to maintain health and improve quality of life to preserve their daily living with better health-promoting behaviour despite the illness that they have (Mohamad, Abdul Mulud, Ibrahim, \& Damanhuri, 2019).

\subsection{Conclusion}

Considering the findings of the present study, and regarding the role of social support towards self-care behaviour, it is essential to improve awareness and education of the importance of establishing good social support for patients with heart failure. Caregivers, especially family members and partners, should be involved in the management and care of heart failure patients.

\section{Acknowledgements}

The authors would like to express their utmost gratitude to all patients and staff who assisted in this study. This study was funded by the Universiti Teknologi MARA Lestari grant [600-IRMI/MYRA 5/3/LESTARI (057/2017)].

\section{References (Max 1 page)}

Årestedt, K., Saveman, B., Johansson, P., \& Blomqvist, K. 2013. Social support and its association with health-related quality of life among older patients with chronic heart failure. European Journal of Cardiovascular Nursing, 12(69). doi: 10.1177/1474515111432997.

Albert, N. M., Fonarow, G. C., Abraham, W. T., et al. (2009). Depression and clinical outcomes in heart failure: An OPTIMIZE-HF analysis. American Journal of Medicine, 122(4), 366-373. 10.1016/j.amjmed.2008.09.046.

Barnes, S., Gott, M., Payne, S., et al. (2006). Prevalence of symptoms in a community-based sample of heart failure patients. Journal of Pain Symptom Management, 32(3), 208-216. doi:http://dx.doi.org/10.1016/

Bekelman, D. B., Dy, S. M., Becker, D. M., et al. (2007). Spiritual well-being and depression in patients with heart failure. Journal of General Internal Medicine, 22(4), 470-477.10.1007/s11606-006-0044-9.

Brännström, M., Ekman, I., Norberg, A., Boman, K., \& Strandberg, G. (2006). Living with severe chronic heart failure in palliative advanced home care. European Journal of Cardiovascular Nursing, 5, 295-302.

Carels, R. A., Musher-Eizenman, D., Cacciapaglia, H., Perez-Benitez, C. I., Christie, S., \& O'Brien, W. (2004). Psychosocial functioning and physical symptoms in heart failure patients: A within-individual approach. Journal of Psychosomatic Research, 56(1), 95-101.10.1016/S0022-3999(03)00041-2

Chan, B., Goldman, E., Sarkar, U., Guzman, D., Critchfield, J., Saha, S., \& Kushel, M. (2019). High perceived social support and hospital readmissions in an older multiethnic, limited English proficiency, safety-net population. BMC Health Services Research, 19, 334. DOI: 10.1186/s12913-019-4162-6.

Conley, S., Feder, S., Redeker, N. S. (2015). The Relationship Between Pain, Fatigue, Depression and Functional Performance in Stable Heart Failure. Heart \& Lung: The Journal of Critical Care, 44(2), 107-112. doi.org/10.1016/j.hrtlng.2014.07.008

Daus, M., Osokpo, O., Brown, S. D., Riegel, B. J. (2018). The Moderating Effect of Social Support in Promoting Self-care in Heart Failure Patients with Comorbid IIInesses. Journal of Cardiac Failure, 24(8S).

Gallagher, R., Luttik, M. L., \& Jaarsma, T. 2011. Social support and self-care in heart failure. Journal of Cardiovascular Nursing, 26(6), 439-445. doi: 10.1097/JCN.0b013e31820984e1. 
Godfrey, C. M., Harrison, M. B., Lysaght, R., et al. (2011). Care of self-care by other care of other: The meaning of self-care from research, practice, policy and industry perspectives. International Journal of Evidence Based Healthcare, 9, 3-24.

Gordon, T., Castelli, W. P., Hjortland, M. C., Kannel, W. B., \& Dawber, T. R. (1977). Diabetes, blood lipids, and the role of obesity in coronary heart disease risk for women. Annals of Internal Medicine, 87, 393-397.

Gordon, T., \& Kannel, W. B. (1982). Multiple risk functions for predicting coronary heart disease: the concept, accuracy, and application. American Heart Journal, 3, 10311039 .

Gottlieb B. Selecting and planning support interventions. (2000). In S. Cohen, L Underwood, \& B. Gotlieb (Eds.), Social support measurement and intervention. London: Oxford University Press

Heo, S., Moser, D. K., Lennie, T. A., Riegel, B., \& Chung, M. L. (2008). Gender differences in and factors related to self-care behaviors: a cross-sectional, correlational study of patients with heart failure. International Journal of Nursing Studies, 45(12), 1807-15.

Jaarsma, T., Årestedt, K. F., Mårtensson, J., Dracup, K., \& Strömberg, A. (2009). The European Heart Failure Self-care Behaviour scale revised into a nine-item scale (EHFScB-9): a reliable and valid international instrument. European Journal of Heart Failure, 11(1), 99-105. doi:10.1093/eurjhf/hfn007.

Jones, C. D., Holmes, G. M., Dewalt, D. A., et al. (2012). Is adherence to weight monitoring or weight based diuretic self-adjustment associated with fewer heart failurerelated emergency department visits or hospitalizations? Journal of Cardiac Failure, 18, 576-584.

Kannel, W. B., \& McGee, D. L. (1979). Diabetes and glucose tolerance as risk factors for cardiovascular disease: the Framingham Study. Diabetes Care, 2,120-126.

Khaledi, G. H., Eslami, A. A., Afza, H. R., Mostafavi, F., \& Akbar, H. 2015. Evaluation of the Effect of Perceived Social Support on Promoting Self Care Behaviors of Heart Failure Patients Referred to The Cardiovascular Research Center of Isfahan. Iran Red Crescent Medical Journal, 17(6). doi: 10.5812/ircmj.22525v2

Mahrer-Imhof, R., Hoffmann, A., \& Froelicher, E. S. 2007. Impact of cardiac disease on couples' relationships. Journal of Advanced Nursing, 57(5), 513-521. doi:10.1111/j.1365-2648.2006.04141.x

Mason, D. T. (1976). Congestive heart failure. New York: York. McK.ee PA, Castelli WP, McNamara PM, Kannell Medical Books, 1.

Ming, L. C., Hassali, M. A., Shafie, A. A., Awaisu, A., Hadi, M. A., \& Al-Haddad, M. (2011). Perspectives of heart failure patients in Malaysia towards medications and disease state management: findings from a qualitative study. Journal of Public Health, 19(6), 569-577.

Lam, C. S. P. (2015). Heart failure in Southeast Asia: facts and numbers. ESC Heart Failure, 2, $46-49$

Mohamad, N., Abdul Mulud, Z., Ibrahim, M., \& Damanhuri, N. (2019). The Relationship between Self-Efficacy and Health Promoting Behaviour among Older Adults with Chronic Illness. Environment-Behaviour Proceeding Journal, 4(11), 73-78.

National Heart Foundation. Health Information: Living Well with Chronic Heart Failure. 2012. Available from: http://www.heartfoundation.org.au/SiteCollectionDocuments/Living-well-with-chronic-heart-failure.pdf (accessed 22 November 2015).

Pedersen, S. S., Spinder, H., Erdman, R. A., \& Denollet, J. (2009). Poor perceived social support in implantable cardioverter defibrillator (ICD) patients and their partners: cross-validation of the multidimensional scale of perceived social support. Psychosomatics, 50(5), 461-467. doi: 10.1176/appi.psy.50.5.461.

Pilisuk, M., Boylan, R., \& Acredolo, C. (1987). Social support, life stress, and subsequent medical care utilization. Health Psychology, 6(4), $273-88$.

Ponikowski, P., Anker, S. D., AlHabib, K. F., Cowie, M. R., Force, T. L., Hu, S. S., Jaarsma, T., Krum, H., Rastogi, V., Rohde, L. E., Samal, U. C., Shimokawa, H., Siswanto, B. B., Sliwa, K., \& Filippatos G. (2014). Heart failure: preventing disease and death worldwide. ESC Heart Failure, 1, 4-25

Riegel, B., \& Dickson, V. A. (2008). Situation-Specific Theory of Heart Failure Self-Care. Journal of Cardiovasc Nursing, 23, 190-196.

Riegel, B., Jaarsma, T. \& Stromberg, A. (2012). A middle-range theory of self-care of chronic illness. Advanced Nursing Science, 35, 194-204

Riegel, B., Moser, D. K., Anker, S. D., Appel, L. J., Dunbar, S. B., Grady, K. L., Gurvitz, M. Z., Havranek, E. P., Lee, C. S., Lindenfeld, J., Peterson, P. N., Pressler, S. J., Schocken, D. D., \& Whellan, D. J. (2009). State of the science: promoting self-care in persons with heart failure: a scientific statement from the American Heart Association. Circulation, 120(12),1141-1163. doi: 10.1161/CIRCULATIONAHA.109.192628

Robyn, G., Marie-Louise, L., Tiny, J. 2011. Social Support and Self-care in Heart Failure. Journal of Cardiovascular Nursing, 26(6), 439-445

Roscoe, J. T. 1975. Fundamental Research Statistics for Behavioural Sciences. 2nd ed. New York: Holt Rinehart \& Winston.

Sakata, Y., \& Shimokawa, H. 2013. Epidemiology of Heart Failure in Asia. Circulation, 77(9), 2209-2217. doi:10.1253/circj.cj-13-0971

Sayers, S. L., Riegel, B., Pawlowski, S., Coyne, J. C., \& Samaha, F. F. 2008. Social Support and Self-Care of Patients with Heart Failure. Annals of Behavioral Medicine, 35(1), 70-79. doi:10.1007/s12160-007-9003-x

Sebern, M., Riegel, B. (2009). Contributions of supportive relationships to heart failure self-care. European Journal of Cardiovascular Nursing: Journal of the Working Group on Cardiovascular Nursing of the European Society of Cardiology, 8(2), 97-104.

Sherbourne, C. D., \& Stewart, A. L. (1991). The MOS Social Support Survey. Social Science \& Medicine, 32(6), 705-714.

Singer, P. A., Martin, D. K., \& Kelner, M. (1999) Quality end-of-life care: patients' perspectives. Journal of American Medical Association, $281,163-1684$.

Stanek, E. J., Oates, M. B., McGhan, W. F., Denofrio, D., \& Loh, E. (2000) Preferences for treatment outcomes in patients with heart failure: symptoms versus survival. Journal of Cardiac Failure, 6, 225-232 
Vellone, E., Jaarsma, T., Strömberg, A., Fida, R., Årestedt, K., Rocco, G. et al. 2014. The European Heart Failure Self-care Behaviour Scale: New insights into factorial structure, reliability, precision and scoring procedure. Patient Education and Counseling, 94(1), 97-102. doi:10.1016/j.pec.2013.09.014

Wagenaar, K. P., Broekhuizen, B. D. L., Rutten, F. H., Stromberg, A., van Stel, H. F., Hoes, A. W., \& Jaarsma, T. (2017). Interpretability of the European Heart Failure Self-care Behavior Scale. Patient Preference and Adherence, 11, 1841-1849.

Yancy, C. W., Mariell, J., Bozkurt, B., Butler, J., Casey, D. E., Drazner, Fonarow, G. C., Geraci, S. A., Horwich, T., Januzzi, J. L., Johnson, M. R., Kasper, E. K., Levy, W. C., Masoudi, F. A. et al. (2013). 2013 ACCF/AHA Guideline for the Management of Heart Failure: Executive Summary. A Report of the American College of Cardiology Foundation/ American Heart Association Task Force on Practice Guidelines Developed in Collaboration with the American College of Chest Physicians, Heart Rhythm Society, and International Society for Heart and Lung Transplantation Endorsed by the American Association of Cardiovascular and Pulmonary Rehabilitation. Journal of the American College of Cardiology, 62(16). doi: http://dx.doi.org/10.1016/j.jacc.2013.05.020

Yunus, H. D., \& Sharoni, S. K. A. (2016). Original Article Social Support and Self-Care Management Among Patients With Chronic Heart Failure. Malaysian Journal of Public Health Medicine, 16(1), 92-98.

Zimet, G. D., Dahlem, N. W., Zimet, S. G., \& Farley, G. K. 1988. The Multidimensional Scale of Perceived Social Support. Journal of Personality Assessment, 52(1), 3041. http://dx.doi.org/10.1207/s15327752jpa5201_2 